\title{
Assessment of Conflict Resolution Training at University
}

\author{
Nadezhda Sivrikova ${ }^{1, *}$, Tatyana Ptashko $^{1}$, Elena Chernikova $^{1}$, Artem Perebeynos ${ }^{1}$, Vitaly Kharlanov $^{2}$ \\ ${ }^{1}$ South Ural State Humanitarian Pedagogical University, Department of Social Work, Pedagogy and Psychology, Chelyabinsk, Russian \\ Federation, Lenin prospect 69 , Russia \\ ${ }^{2}$ South Ural State University, Legal institute, Department of Theory of State and Law, Constitutional and Administrative Law, Russian \\ Federation, Chelyabinsk, Lenin prospect 76 , Russia
}

\begin{abstract}
The growth of conflicts in a changing world makes conflict resolution competence an important component of entrepreneurial competencies. Higher education should empower students to effectively prevent and resolve conflicts. The problem of assessing the educational process in the field of conflict resolution training and the result of this training is discussed in this article. The authors cite the results of an empirical study, the purpose of which was to determine the needs of students of the State University (Chelyabinsk, Russia) with regards to conflict management preparation. The survey relied on an analysis of the self-assessment of students' own skills and commitment to the principles of tolerance, an assessment of the educational process, and the need to increase their own conflict management competence. 152 students of the State University took part in the survey, of which 63 were male and 89 female. The Likert scale was used. The results of the study showed that students assess the level of their own conflict resolution competence as high, as do they the educational process at the university. The limitations of the study are discussed at the end of the article.
\end{abstract}

Keywords: conflict resolution competence, higher education, conflict management, conflict resolution training, entrepreneurial competencies

\section{Introduction}

The existence of objective contradictions in the educational process makes it inevitable that conflicts arise between the participants of the educational process [1]. Conflict management is an essential component of teaching. It is only through it that the peaceful coexistence of the subjects of the educational process can be ensured [2], the conflict resolution competence of children develop [3], and the psychological climate in schools be favourable [3]. Therefore, professionals who need to meet the modern requirements of the labour market should be ready for conflict prevention and resolution [4].

The need for conflict management training is raised by employers, students and teachers alike. Competencies related to conflict management are present in all professions as standard. Social competence, which includes the ability to manage conflicts, is at the top of the list of key competencies needed to successfully operate as a professional in any field [5]. Students in many assisting professions speak of their desire to increase their own training in conflict resolution, e.g. health workers [6, 7], staff managers [8] and teachers [2, 9, 10]. However, there is a lack of data on how existing conflict management training at universities is assessed. Therefore, the purpose of the research presented in this paper was to study how students at the State University (Chelyabinsk, Russia) assessment their conflict management training.

In scientific literature, the problems of assessing the quality of conflict management training are presented at different levels. As part of the discussion of the prospects for the development of vocational education, the ability to establish educational programs to ensure the formation of a conflict management culture is analysed [5], as is the conflict management competence [1] of future specialists. Scientists also discuss the effective conflict management techniques that a teacher should possess $[4,9,10]$. They recognize that teachers should be encouraged, as a strategic training line, to acquire opportunities to properly manage conflict and social relations [2].

Studies on the development of courses and programs to develop conflict competence indicate a low level of competence in the field of conflict management if there is no focused work in this direction [10-12]. Researchers who compared the level of conflict culture in students of different specialities came to a similar conclusion [5]. A more optimistic picture is presented in the results of student self-assessments with regards to the formation of their knowledge and skills in the field of conflict resolution [13]. These studies conclude that there is a need to improve conflict management training programs at universities, too.

\footnotetext{
${ }^{*}$ Corresponding author: bobronv@cspu.ru
} 
The level of conflict management training is assessed through qualitative studies aimed at analysing problems and ways of resolving conflicts used by practitioners [14-16].

The assessment of the quality of student training in conflict resolution is therefore based on different methodological principles. However, it is generally not an independent focus of study. Findings on the need to improve conflict management training are based on indirect data. Therefore, it is important to study students' views on the quality of their preparation for conflict resolution.

The assessment of the conflict resolution training of future specialists is comprehensive. This is because being prepared for conflicts in itself represents a complex phenomenon. Bisembayeva believes that its structure includes: conflict knowledge, skills, mastery of diagnostic techniques, forecasting, prevention and resolution of conflicts [12]. Other researchers from Kazakhstan describe the structure of conflict competence as a set of personal, motivational, meaningful, behavioural and reflexive components [11]. Spanish researchers view this from a classical competency structure that includes knowledge, ability and skills [2].

Many researchers view conflict behaviour strategies as an important indicator of conflict resolution training. They believe that constructive behaviour in a conflict situation can contribute to achieving a higher level of development of the cooperating parties. Researchers have shown that mediators are more likely to choose pro-social conflict resolution strategies, and their colleagues without special training are more likely to choose a care strategy [17].

In addition to assessing the level of knowledge, ability and skills in the field of conflict management, the assessment of conflict resolution training includes taking into account two other criteria: compliance of the educational program with the tasks of conflict readiness preparation [1] and the need of students for conflict resolution training [2].

As a result, three criteria for assessing conflict resolution training in university are considered in this study. These are a self-assessment of the level of strength of personal skills and abilities related to conflict management, compliance of the educational program with the tasks of conflict readiness preparation, and the need for conflict resolution training.

The aim of the study was to determine the need of university students for training in conflict management.

\section{Methodology}

The survey of students of the Department of Pedagogics of the State University (Chelyabinsk, Russia) was conducted in 2020. In total, 152 students (63 male and 89 female) participated in the survey. The distribution of the participants according to study year is shown in Table 1.

Table 1. Characteristics of the research participants $(n=152)$

\begin{tabular}{|c|c|}
\hline Year of study & Number of people (\%) \\
\hline 2 & $56.9 \%$ \\
\hline 3 & $19.6 \%$ \\
\hline 4 & $17 \%$ \\
\hline 5 & $7.8 \%$ \\
\hline
\end{tabular}

Source: Authors.

The survey consisted of 17 questions, each with a 5-point response scale (1. Completely disagree; 2. Disagree; 3. I don't know; 4. Agree; 5. Completely agree). The developed tool enabled the evaluation of three variables: 1. Representation of conflict training elements in training; 2. Self-assessment of the skills and abilities required for effective conflict resolution; 3. Need for conflict training. The Alpha Cronbach correlation coefficient was used to determine the reliability (internal consistency) of the developed instrument. The coefficients for the different questionnaire blocks ranged from 0.938 to 0.716 , which is acceptable.

A descriptive and quantitative analysis of the information collected was carried out. IBM SPSS Statistics 23 software was used for mathematical processing of the results.

\section{Results and Discussions}

The findings show (see Table 2) that, in general, students believe their own conflict resolution skills to be high (sample averages approach 4 points on the Likert scale).

The participants of the study assessed the level of their own skills with regards to a) recognising the meanings of messages depending on the context of the communication situation, and b) predicting the actions of people on the basis of the analysis of real situations, below that of other skills. Despite this, the students still rated their skills as more than satisfactory. Students believe that they possess the skills to perceive and interpret the personality of others, and that these skills are more developed than their other skills. 
Students rate their own commitment to the principles of tolerance quite highly (see Table 3). Sample averages approach 4 points.

Students who took part in the study rate their own internal resilience below other principles. The largest number of students noted that they fully agreed that they followed the principle of non-violence $(80 \%)$.

Students highly appreciate the system of conflict resolution training at the university (see Table 4). They partially $(40.6 \%)$ or completely $(48.4 \%)$ agree that the educational process at the university prepares students for the employment functions related to the resolution of conflicts. At the same time, only $21.3 \%$ indicated that they have no need to increase their own conflict resolution competence, with up to $74.8 \%$ stating they do.

Table 2. Results of students' self-assessment of conflict resolution skills ( $\mathrm{n}=152)$

\begin{tabular}{|c|c|c|c|c|c|c|c|}
\hline \multirow{2}{*}{ Studied parameters } & \multicolumn{5}{|c|}{ Likert response option $(\%)$} & \multirow{2}{*}{$\begin{array}{l}\text { mean } \\
\text { value }\end{array}$} & \multirow{2}{*}{$\begin{array}{c}\text { standard } \\
\text { deviation }\end{array}$} \\
\hline & 1 & 2 & 3 & 4 & 5 & & \\
\hline $\begin{array}{l}\text { Adequacy of perception and interpretation of } \\
\text { another's personality }\end{array}$ & 0.6 & 2.6 & 4.5 & 56.8 & 35.5 & 4.24 & 0.72 \\
\hline $\begin{array}{l}\text { Adequacy of evaluation of emotional state by } \\
\text { non-verbal reactions }\end{array}$ & 0.6 & 4.5 & 17.4 & 46.5 & 31.0 & 4.03 & 0.86 \\
\hline $\begin{array}{l}\text { Recognition of the meaning of verbal messages } \\
\text { depending on the context of the communication } \\
\text { situation }\end{array}$ & 1.3 & 3.9 & 27.7 & 52.3 & 14.8 & 3.76 & 0.80 \\
\hline $\begin{array}{l}\text { Predicting people's actions based on real situation } \\
\text { analysis }\end{array}$ & 0.0 & 7.1 & 17.4 & 57.4 & 18.1 & 3.86 & 0.80 \\
\hline Reflexive hearing & 0.6 & 6.5 & 20.6 & 40.0 & 32.3 & 3.96 & 0.92 \\
\hline $\begin{array}{l}\text { Analysis and evaluation of actions of conflicting } \\
\text { parties }\end{array}$ & 0.0 & 3.9 & 16.1 & 42.6 & 37.4 & 4.12 & 0.82 \\
\hline Making responsible and informed decisions & 0.0 & 5.2 & 12.9 & 47.1 & 34.8 & 4.12 & 0.83 \\
\hline
\end{tabular}

Source: Authors.

Table 3. Results of students' self-assessment of acceptance of the principles of tolerance and non-violence ( $\mathrm{n}=152)$

\begin{tabular}{|c|c|c|c|c|c|c|c|}
\hline \multirow{2}{*}{ Studied parameters } & \multicolumn{5}{|c|}{ Likert response option (\%) } & \multirow{2}{*}{ Mean value } & \multirow{2}{*}{ Standard deviation } \\
\hline & 1 & 2 & 3 & 4 & 5 & & \\
\hline Position as equals & 0.6 & 3.9 & 16.8 & 45.8 & 32.9 & 4.07 & 0.85 \\
\hline Refusal of violence & 2.6 & 3.2 & 6.5 & 7.7 & 80.0 & 4.59 & 0.94 \\
\hline Submission to rules & 1.9 & 3.2 & 11.0 & 35.5 & 48.4 & 4.24 & 0.92 \\
\hline Positive purposes & 1.9 & 2.6 & 11.6 & 36.1 & 47.7 & 4.25 & 0.91 \\
\hline Internal stability & 4.5 & 3.2 & 21.9 & 38.1 & 32.3 & 3.91 & 1.04 \\
\hline Personal choice & 1.9 & 1.9 & 20.6 & 34.2 & 41.3 & 4.10 & 0.93 \\
\hline
\end{tabular}

Source: Authors.

Table 4. Students' self-assessment of system of conflict resolution training and need to increase preparedness ( $\mathrm{n}=152)$

\begin{tabular}{|l|c|c|c|c|c|c|c|}
\hline \multirow{2}{*}{ Studied parameters } & \multicolumn{3}{|c|}{ Likert Response Option (\%) } & \multirow{2}{*}{ Mean value } & \multirow{2}{*}{ Standard deviation } \\
\cline { 2 - 5 } & 1 & 2 & 3 & 4 & 5 & & 0.86 \\
\hline $\begin{array}{l}\text { Assessment of the conflict training } \\
\text { system at the university }\end{array}$ & 1.9 & 2.6 & 6.5 & 40.6 & 48.4 & 4.31 & 0.50 \\
\hline $\begin{array}{l}\text { Need to increase conflict resolution } \\
\text { competence }\end{array}$ & 21.3 & 0.0 & 1.3 & 2.6 & 74.8 & 4.1 & 0 \\
\hline
\end{tabular}

Source: Authors.

\section{Conclusion}

The results of the study make it possible to conclude that students of the State University assess the level of their own conflict resolution competence as high, as they do the elements of the educational process at the university. However, at the same time, many of them feel that there is room for improvement on this front.

It should be noted that the study presented has a number of limitations. First, the conclusions are drawn from an analysis of student self-assessments, which are subject to social desirability factors. This is especially true for assessing the level of conflict competence. 
Secondly, students of different courses took part in the presented study, and the studied variables are dynamic and vary depending on the degree of mastery of the educational program.

The study also does not analyse the profession being mastered by the respondents.

Despite the aforementioned limitations, the results of the study contribute to the evaluation of conflict resolution training at the university. They can serve as a basis for changing existing or developing new educational programs.

\section{References}

1. M. G. Sergeeva, N. M. Simonova, E. Y. Pryazhnikova, Y. A. Volkova, and T. M. Rozhnova, Technology of pedagogical conflict management within an educational institution. Revista Inclusiones. 7, 217-228 (2020)

2. M. C. Lopez Lopez, R. Tejero Olmedo, and A. Fernandez Herreria, School conflict and its management in initial teacher training. A case study. Profesorado-Revista De Curriculum Y Formacion De Profesorado. 21, 293-314 (2017)

3. L. García-Raga, R. M. B. Bonet, and J. M. Lasagabaster, Meaning and sense of school mediation based on high school mediators' views. Revista Espanola de Orientacion y Psicopedagogia. 29, 79-93 (2018)

4. S. A. Djumaeva, Technology for the Elimination of Conflicts in the Process of Higher Education by Means of Pedagogical Correction. International Journal of Innovative Technology and Exploring Engineering. 9, 2670-2676 (2020)

5. O. Shcherbakova and A. Tatarinceva, Conflictological culture of personality in a professional environment (by the example of pedagogues and engineers). Society. Integration. Education: Proceedings of the International Scientific Conference. 1, 524 (2016)

6. F. K. Cheng, Mediation skills for conflict resolution in nursing education. Nurse Education in Practice. 15 (2015)

7. S. Vandergoot, A. Sarris, N. Kirby, and H. Ward, Exploring undergraduate students' attitudes towards interprofessional learning, motivation-to-learn, and perceived impact of learning conflict resolution skills. $J$. Interprof. Care. 32, 211-219 (2018)

8. E. A. Karpova, Development prospects of conflictological competence. Akmeology. 248-256 (2015)

9. Y. del C. Camacho Sojo, Mediation in conflicts: challenges in the on-going education of elementary school teachers. Revista de Mediación. 11 (2018)

10. N. Gunduz, H. Uzunboylu, and D. Ozcan, Developing and testing a scale to assess teachers' attitudes toward peer mediation of student disputes. Social Behavior and Personality. 45, 1745-1760 (2017)

11. M. B. Alpysbayeva, Z. A. Karmanova, V. V. Bobrova, A. M. Sharzadin, and R. B. Mazhenova, Development of conflict management competency in social work undergraduate students. Science for Education Today. 9, 58-80 (2019)

12. K. Bisembayeva, N. V. Sivrikova, Formation of conflictological competence of future educational psychologists. Herald of South Ural State Humanitarian Pedagogical University bulletin. 147-154 (2018)

13. P. Iranzo-García, M. Camarero-Figuerola, C. Barrios-Arós, J. M. a. Tierno-García, S. Gilabert-Medina, What do teachers think about school leadership competences and their pre-service training?. REICE. Revista Iberoamericana Sobre Calidad, Eficacia y Cambio en Educacion. 16, 29-48 (2018)

14. E. M. Blunk, E. M. Russell, C. J. Armga, The role of teachers in peer conflict: implications for teacher reflections. Teacher Development. 21, 597-608 (2017)

15. G. Ciuladiene, R. Raudeliunaite, Peer mediation as tool to resolve school based conflitcs: the opinion of an school staff (case study). EDULEARN Proceedings: 8th International Conference on Education and New Learning Technologies. 16, (2016)

16. E. P. da Costa, S. Sá, Teacher Narratives on the Practice of Conflict Mediation. Advances in Intelligent Systems and Computing. 861, (2019)

17. R. Pulido, T. Fajardo, L. Pleguezuelos, R. De Gregorio, and P. Educativa, School mediation in the region of Madrid: analyzing the impact of education on teachers and students at the 'Las Americas' high school in Parla. Revista de Mediación. 3, 32-43 (2010) 